\title{
The Communicative Preferences of Technical University Students in Social Networks
}

\author{
Natalia Semenova ${ }^{1, a *}$, Natalia Lebedeva ${ }^{1}$, Elena Polyakova ${ }^{2}$ \\ 1 Saint Petersburg State University of Civil Aviation, Language Training Department, 196210, 38 \\ Pilotov str, Russia \\ 2 National Research Nuclear University MEPhl (Moscow Engineering Physics Institute), \\ Department of Foreign Languages, 115409, 31 Kashirskoe shosse, Russia \\ anvsemenova@mail.ru \\ ${ }^{*}$ Corresponding author
}

Keywords: online social networks, university students, technical professions, Russia

\begin{abstract}
The paper focuses on social networking activities of university students from the National Research Nuclear University MEPhI (Moscow Engineering Physics Institute) and Saint Petersburg State University of Civil Aviation. The authors make an attempt to determine the network communicative preferences of students that train for technical professions. The choice of the universities is motivated by the strategic importance of the professions obtained by their graduates. Respondents' preferences in using various social networks for the instructions were detected by the questionnaire described below. The results show strong preference of VK, Instagram, Facebook, but in practice, reflecting the access rate, only VK could be used for education purposes. It was noted that the network preferences of the students from both technical universities are in line with the general Russian trends. And though online social networks (OSNs) are used by them mostly for the sake of rest and recreation, for communicating with friends, the students show that they are greatly interested in accumulating their social and professional capital by means of OSNs. This fact runs counter to their evaluation of the content offered by the contemporary professionally oriented network communities, with which they are not satisfied.
\end{abstract}

\section{Introduction}

The sphere of online social networking that gave rise to various types of online social networks (OSNs) had in a short time become global. OSNs are now being used by approximately one third of our planet's population. Evidently, OSNs had come to the fore as a result of the stage of Internet technologies development that is known now under the name of Web 2.0. The basic principle of Web 2.0 is attracting the users in multitudes to filling and verifying its content recurrently. It means that OSNs presuppose mass user "by nature". It is quite natural that the major part of users is comprised of young people as representatives of a new digital generation ("generation Y", or "millennials"). According to the data of such giants as Facebook, Twitter, MySpace and the Russian leader VK, average OSN users are aged 18-34. Users aged 18-24, i.e. those who call themselves Digital Native, are by far the most active. First off, young people are attracted by OSNs due to the availability of a free choice of an information source when any manipulative influence on the part of official mass media is ruled out, and the speed of transmitting own information to a large number of people without the loss of efficient interaction between the communicants. Among other things, one of the most important effects of such interactive networking is the change in the mechanism that generates the list of key issues of public interest: equipped with OSN tools, young people are much quicker in searching, generating and spreading relevant information than official media sources. Thus, for young people the process of shaping the "official agenda" runs somewhat parallel to the state of affairs covered by the official media. Now that discussing fake news is becoming a global trend, it is evident that one of the most critical tasks for contemporary information-oriented society is to understand and interpret social implications of the phenomenon of online social communication. Another reason to reflect on how online information sources influence the young people is active implementation of OSNs in higher education. It is facilitated by the development of e-learning system as well as its branch - m-learning, and even the paradigm of $\mathrm{u}$-learning (ubiquitous learning), that is beginning to take shape. 
The goal of the article is to find out the communicative preferences in the sphere of online activity of students from two technical universities in Moscow and in Saint Petersburg - Russian centers of higher education. The immediate objectives for this study were to determine the student's preferences on the web, ways of their self-identification and self-presentation, scope of their web interests, the students' evaluation of OSNs as an instrument of sociocultural communications as well as some other aspects in order to find out if the students' professional activity in OSNs is existent/non-existent.

\section{Theoretical Background of Study}

\subsection{Presentation of a Problem}

The first serious research into social networking in higher education was conducted abroad in the framework of Social Network Analysis (SNA). As pointed out by experts, from a specialized and relatively unknown methods of social science, in less than half a century SNA turned into a wide variety of techniques and methods that help to solve different research tasks in different fields of science. It became possible because "by being focused on the connections between people and organizations, SNA gave researchers an opportunity to go beyond the limits of methodological individualism that was typical of most last-century studies in the field of education and social sciences, thus broadening and enriching the understanding of socials aspects of higher education" [1, p. 85].

The analysis of social interaction networks in the framework of educational field was initially oriented on studying such dyads as "student - student," "teacher - teacher" and "student - teacher". In this respect, the history of foreign studies is very well covered by the study of the above-mentioned authors S. Biancani and D. McFarland. But, as a rule, all the issues that interested SNA while studying educational societies, came down to the following: 1) the analysis of teachers' or students' network of friendship and assistance; 2) determining the factors that influence the initiation of friendly relations within universities, colleges or residence halls; 3 ) disclosure of factors that influence students' racial and ethical attitudes; 4) finding out the mechanisms of homophilia and intimacy; 5) characterizing students' attitudes that influence academic achievements (see e.g. $[2 ; 3]$ ). With the advent of OSNs and their gaining the popularity, SNA techniques became widespread. From then on, social network came to be considered as a social structure with its underlying rationale provided way back in the sociometry of Jacob L. Moreno, as well as its specific implementation on the Internet. The sphere of the questions under consideration remained practically the same. True enough, now it came to be supplemented by purely technical issues related to creation of own profile on the Web, as well as the problems of privacy and security. Besides, the latter are now becoming extremely essential owing to the mass user changeover to the Mobile Social Network (see e.g. [4]). Social Media Marketing (SMM) came to be regarded as a separate branch of OSNs studies, which is now much-indemand due to the intensive development of IoT sector.

Domestic studies devoted to the description of students' online social networking are by way below in number as compared to foreign research. Nevertheless, the fact that the Russian user that had discovered the Internet relatively late, is actively and successfully integrating into the World Wide Web could not but provoke the scientists' interest. In the first place, OSNs attracted the attention of Russian researchers with respect to information security and informational influence, value, or utility of the new phenomenon, as well as in connection with studying users' behavior on the Web. It is from this viewpoint that the key OSN features were characterized (such as the agent, opinion, influence/trust, reputation), as well as the common features of social networks. (see e.g. [5]). In 2015, A.D. Voloshinova analyzed 2958 Russian publications where social networks had been mentioned, one way or another. It turned out that only 532 studies could be considered as pursuing this relatively narrow subject. 357 of them $(67 \%)$ happened to be sociopsychologically-oriented, $134(25.3 \%)$ were focused on pedagogy, $41(7.7 \%)$ - on mathematics/informatics. The major part of contributions fell on 2011 and 2012. As a rule, the research was centered around spreading the information in social networks and establishing the relations between the elements of a social network. It is noteworthy that social networks were considered both in a broad sense as a system of communication network between people, and in a narrow sense - as OSNs [6]. The traditional range of SNA problems related to exploring the social network in education was analyzed by only a few researchers (see e.g. [7]). Naturally, it will be only just to mention that Russian teachers were interested in the gigantic educational opportunities offered by OSNs from the very moment of their appearance, but their interest was purely practical - as a new educational technique (see e.g. [8]). 
As a matter of fact, now it is time for detailed investigation into the social networking activity of Russia's younger generation, and above all - students. But in our opinion, prior to beginning with SNA at a given university or within a network of a particular course participants, or students studying for a particular occupation, a detailed research should be done into OSNs popular with the students. And the first stepping stone is to describe their communicative preferences, which is the main goal of our research. But the result of such description will not be objective unless it is integrated into a wider "digital" context.

\subsection{Russian trends of social networks}

According to official data, in March 2018 more than a half of the planet's population had access to the World Wide Web - 4 billion people, one fourth of which had no prior experience with the Internet. In January 2018, the number of OSN users amounted to 3.196 billion people - and it is up 13 percent year-onyear. Facebook still remains the world's most popular social network: in March the number of its users have grown close to reaching 2.2 billion users (2.167). Second best is Youtube - 1.8 billion users. The last of top three leaders is the Instagram social network that reports 800.000 .000 million active users and that, as we know, was taken over by Facebook in 2012 (see e.g. [9; 10; 11]). In course of 2017, much in accord with the general expectations, messenger popularity was growing, so that they had outnumbered many OSNs that were traditionally in demand as regards user growth. The most frequently used messengers are those that either represent a special Facebook tool, or belong to Facebook company: WatsApp accounts for 1.5 billion people, Messenger FB - 1.3 billion. According to experts, the considerable user growth of these social services can be explained by mass users change-over to smartphones implementing the BYOD principle (bring your own device).

Even this brief statistic information demonstrates that practically all the planet's Internet-active population now uses OSNs; secondly, that the absolute monopoly in this sphere belongs to Facebook, which by possessing the most speedy and desired social networking tools, naturally becomes a monopolist in the information policy of network communities. Against this backdrop, Russian OSN user presents a unique phenomenon. The absolute leader of Russian OSN users is VK. Russia is the only country in the world that possesses own OSN which is so popular. If we ask why Facebook has ceded leadership to VK in Russia, the first explanation that comes to mind is that at the time it appeared and became widespread, Facebook had only English interface (it is as late as in 2008 that the Russian version appeared), and the majority of Russian users didn't have a free command of the English language. Whereas VK based on the native language of Russian users has been actively functioning since 2006. But this by no means explains why Russian VK user community outnumbers that of Facebook, now that the latter has a Russian version, and its active user is quite different.

In spite of the fact that, according to the data from Levada-Center announced in March 2018, there was a sudden downturn as regards interest in OSNs - the number of OSN users among adult Russians amounts to $59 \%$, which is $7 \%$ less than in March - VK remains the most popular OSN: the number of its users has increased by 5\% [12]. But on the whole, the VK network is reached by 97 million users. In March over 24 million active authors was recorded, that have generated more than 300 million messages. VK is a network for youths: $38 \%$ are aged $25-34$, and over one fourth of the authors belong to a still younger generation $(23 \%)-18-24$ years old [13]. According to figures from the research of Mail.Ru Group conducted in 2017, VK is used by $93 \%$ of young Russians aged 14-25 [14], which means that almost all students of higher educational institutions in Russia have a VK profile. According to the statistical data provided by the Russian Public Opinion Research Center, almost one third of VK users (28\%) goes online every day. Running second in popularity are Odnoklassniky (19\%), Instagram (14\%), Google (7\%), Facebook and My World (4\% each), Twitter and LiveJournal (1\% each). Just like VK, Instagram represents a predominantly "youthful" network: the majority of its users are aged 18-24 (38\%). 84\% of VK users and $92 \%$ of Instagram users $\log$ onto the net via mobile devices - telephones/smartphones. As reported by the Russian Public Opinion Research Center, young people use messengers such as WhatsApp (44\%) or VK messenger (32\%) much more often than the older generation (see e.g. [15].

VK is especially popular in the North-West of Russia: the percent of its reach is very high. Among the leaders are Saint Petersburg (29.87\%), Murmansk Region (20.89\%), the Republic of Karelia (20.29\%); within $17-19 \%$ are Arkhangelsk, Vologda and Kaliningrad Regions. In March VK was also popular in Sevastopol (19.17\%). The percent of VK reach in Moscow is not very high $17.08 \%$, but then in March 
Moscow showed Russia's highest percent of Facebook reach - 8.75\% (to compare: 3,85\% in Saint Petersburg, $1.08 \%$ in Murmansk Region, $0.74 \%$ in the Republic of Karelia; $0.03 \%$ in Sevastopol). Facebook is popular in Siberia and in the Far East, whereas its demand in the North-West and in the Central Russia is practically nonexistent. The Moscovites logged onto Instagram quite often in March (26.68\%), surprisingly enough Instagram was in demand in Sevastopol (25.14\%), while Saint Petersburg ranked third with its $24.40 \%$ of reach. There are no other statistical data as regards regional preferences for Instagram. Social networks are in the least demand in the Caucasus Region and in Jewish Autonomous Region.

In this respect, the analysis of the communicative OSN field of students from the two Russia's major educational centers - Moscow and Saint Petersburg - is of great importance. It is especially relevant with respect to the students of technical universities since engineering professions are considered trendy in the framework of Russian policy for modernization in higher education.

\section{Methodology}

We have conducted a survey based on the data obtained from distributing questionnaires among the students of the two higher educational institutions: National Research Nuclear University MEPhI (Moscow Engineering Physics Institute) and SPbGUCA (Saint Petersburg State University of Civil Aviation). These are two technical universities that provide bachelor's, master's and specialist's degree programs for industries of strategical importance - nuclear power and aviation. The survey was based on the method of spreading anonymous online questionnaires created by means of Google forms. The questionnaires were filled in by 122 students from National Research Nuclear University MEPhI and 114 students from Saint Petersburg State University of Civil Aviation. Over $70 \%$ of both university participants are male (75.4\% $\mathrm{MEPhI}$ and $60.5 \% \mathrm{SPbGUCA}$ ), more than $90 \%$ are aged $18-25$ years old ( $96.7 \%$ and $91.2 \%$ respectively).

The questionnaire consisted of 25 questions; both direct and indirect questions were used, of open and closed type (with fixed variants of answers). The survey was guided by these principles: it should be a) voluntary, b) anonymous, c) informative, d) impartial and independent, e) based on standard procedures and frameworks of reference. Five indicators have been chosen for the sake of unified assessment: Indicator $1-$ the degree of the students' interest in using OSNs; Indicator 2 - the degree of the students' involvement in OSNs; Indicator 3 - communicative priorities in OSNs; Indicator 4 - social benefit from using OSNs; Indicator 5 - evaluation of OSNs in augmenting the social and professional store of knowledge.

\section{Results}

OSNs are used by $97.5 \%$ of MEPhI respondents and $98.2 \%$ of SPbGUCA's. Only 2 students of SPbGUCA have no profile in any of the existing OSNs, 3 students of MEPhI have profiles but do not access them. The questions about the reasons were answered in the following manner: "I don't want to and have no time". Students of both the universities have had their profiles in OSNs for over 5 years. The main reason why they choose communication via OSNs was identified by $79.5 \%$ of MEPhI and $83.3 \%$ of SPbGUCA students as "convenience of communication". 40.2\% of MEPhI's respondents and 45.6\% of SPbGUCA's respondents use OSNs because they are logged onto by the majority of their friends. In conformity with Russia's general trend, the demand for VK was the greatest. The following Table 1 fully reflects the network preferences of the respondents that have filled in the questionnaires.

TABLE 1. STUDENTS' NETWORK PREFERENCES.

\begin{tabular}{lcc}
\hline \multicolumn{1}{c}{$\begin{array}{c}\text { Profile } \\
\text { on OSNs }\end{array}$} & $\begin{array}{c}\text { National Research Nuclear } \\
\text { University MEPhI } \\
\text { (persons, } \%)\end{array}$ & $\begin{array}{c}\text { Saint Petersburg State University } \\
\text { of Civil Aviation } \\
\text { (persons, \%) }\end{array}$ \\
\hline VK & $119(97.5 \%)$ & $106(98.2 \%)$ \\
\hline Odnoklassniki & $1(0.8 \%)$ & $20(17.5 \%)$ \\
\hline My World & $2(1.6 \%)$ & $20(17.5 \%)$ \\
\hline Instagram & $37(30.3 \%)$ & $82(71.9 \%)$ \\
\hline Facebook & $4(3.3 \%)$ & $53(46.5 \%)$ \\
\hline Flickr & 0 & $2(1.8 \%)$ \\
\hline Google+ & $5(4.1 \%)$ & $49(43 \%)$ \\
\hline
\end{tabular}




\begin{tabular}{lcc}
\hline Twitter & $11(9 \%)$ & $33(28.9 \%)$ \\
\hline Telegram & $2(1.6 \%)$ & $4(3.5 \%)$ \\
\hline LiveJournal & $1(0.8 \%)$ & $4(3.5 \%)$ \\
\hline MySpace & 0 & $2(1.8 \%)$ \\
\hline Pinterest & 0 & $8(7 \%)$ \\
\hline
\end{tabular}

As a rule, students have one account per OSN. But $16.4 \%$ of MEPhI students and $20.2 \%$ of SPbGUCA students prefer using two accounts within one OSN. As a rule, the students of both universities have as many as 50 to 100 online friends, usually they have met in person. $50.8 \%$ of respondents from MEPhI and $59.6 \%$ respondents from SPbGUCA think that their communication with those around them is not affected by OSNs. $94.3 \%$ and $94.7 \%$ of students from both the universities check on their network account every day. Students' answers to the question regarding the amount of time that they spend every day on social networks are shown in Table 2.

TABLE 2. DAILY AMOUNT OF TIME SPENT ON SOCIAL NETWORKS.

\begin{tabular}{lcc}
\hline \multicolumn{1}{c}{$\begin{array}{c}\text { Amount } \\
\text { of time }\end{array}$} & $\begin{array}{c}\text { National Research Nuclear } \\
\text { University MEPhI } \\
\text { (persons, } \%)\end{array}$ & $\begin{array}{c}\text { Saint Petersburg State University of } \\
\text { Civil Aviation } \\
\text { (persons, \%) }\end{array}$ \\
\hline $15-20$ minutes & $9(7.4 \%)$ & $15(13.2 \%)$ \\
\hline $\begin{array}{l}20 \text { minutes to } \\
1 \text { hour }\end{array}$ & $27(22.1 \%)$ & $28(24.6 \%)$ \\
\hline 1 to 3 hours & $49(40.2 \%)$ & $35(30.7 \%)$ \\
\hline over 3 hours & $37(30.3 \%)$ & $36(31.6 \%)$ \\
\hline
\end{tabular}

Students from both the universities gave the same answer to the question about self-presentation, saying that they add to their profile the absolute minimum required for registration. Only $4.9 \%$ of respondents from MEPhI and $11.4 \%$ of those from SPbGUCA added maximum information about themselves. $2.6 \%$ and $5.7 \%$ respectively prefer anonymous communication in OSNs. Also, one of the main disadvantages of OSNs is seen by the students as unreliable confidentiality and authenticity of information. The majority of both universities' respondents (67\% MEPhI, 71\% SPbGUCA) are concerned with the security policy as regards personal data. Students from both the universities dislike the appearance of paid content on the OSNs (especially music on VK), as well as lots of commercials. Students are willing to pay a reasonable price for using OSNs $(52.5 \% \mathrm{MEPhI}, 71.1 \% \mathrm{SPbGUCA})$, while the percentage of those who is not ready to do so is also quite high - $41 \% \mathrm{MEPhI}, 24.6 \% \mathrm{SPbGUCA}$. More than a half of the respondents is not ready to delete their accounts in OSNs as they contain important information. The answers to the question "Did you stop visiting OSNs as frequently as before?" are presented in Table 3.

TABLE 3. INTEREST IN OSNS.

\begin{tabular}{lcc}
\hline Heading & $\begin{array}{c}\text { National Research Nuclear } \\
\text { University MEPhI } \\
\text { (persons, \%) }\end{array}$ & $\begin{array}{c}\text { Saint Petersburg State University of } \\
\text { Civil Aviation } \\
\text { (persons, \%) }\end{array}$ \\
\hline Yes & $23(18.9 \%)$ & $12(10.5 \%)$ \\
\hline Rather yes & $28(23 \%)$ & $35(30.7 \%)$ \\
\hline No & $35(28.7 \%)$ & $40(35.1 \%)$ \\
Rather no & $36(29.5 \%)$ & $27(23.7 \%)$ \\
\hline
\end{tabular}

Practically all the students are attracted by OSNs owing to: communication with friends/relatives/acquaintances $(89.3 \%$ - MEPhI, 92.1\% - SPbGUCA), listening to the music $(72.1 \%$ MEPhI, 78.1\% - SPbGUCA), watching videos (37.7\% - MEPhI, 56.1\% - SPbGUCA). 23\% of MEPhI students and $36 \%$ of SPbGUCA students are attracted by the convenient search of professionally oriented information provided by OSNs. Over $70 \%$ of respondents from both the universities are not using but would like to use OSNs for professional communication. On the whole, thematic preferences of students shown by their group membership are presented in Table 4. 
TABLE 4. THEMATIC PREFERENCES.

\begin{tabular}{|c|c|c|}
\hline Heading & $\begin{array}{l}\text { National Research Nuclear } \\
\text { University MEPhI } \\
\text { (persons, \%) }\end{array}$ & $\begin{array}{c}\text { Saint Petersburg State University of Civil } \\
\text { Aviation } \\
(\text { persons, \%) }\end{array}$ \\
\hline Humour & $81(64.4 \%)$ & $77(67.5 \%)$ \\
\hline Health & $20(16.4 \%)$ & $23(20.2 \%)$ \\
\hline News & $54(44.3 \%)$ & $68(59.6 \%)$ \\
\hline Food, recipes & $29(23.8)$ & $36(31.6 \%)$ \\
\hline Travel & $33(27 \%)$ & $54(47.4 \%)$ \\
\hline Sport & $41(33.6 \%)$ & $46(40.4 \%)$ \\
\hline Fashion & $28(23 \%)$ & $32(28.1 \%)$ \\
\hline$\underline{\text { Culture and art }}$ & $52(42.6 \%)$ & $39(34.2 \%)$ \\
\hline Economy & $16(13.1 \%)$ & $27(23.7 \%)$ \\
\hline Territorial gr. & $24(19.7 \%)$ & $25(21.9 \%)$ \\
\hline Psychology & $22(18 \%)$ & $31(27.2 \%)$ \\
\hline Religion & $7(5.7 \%)$ & $4(3.5 \%)$ \\
\hline Professional gr. & $32(26.2 \%)$ & $32(28.1 \%)$ \\
\hline Educational gr. & $61(50 \%)$ & $62(54.4 \%)$ \\
\hline $\begin{array}{l}\text { Science, } \\
\text { equipment }\end{array}$ & $71(58.2 \%)$ & $58(50.9 \%)$ \\
\hline Education & $58(47.5 \%)$ & $51(44.7 \%)$ \\
\hline Cars & $13(10.7)$ & $36(31.6 \%)$ \\
\hline Policy & $20(16.4 \%)$ & $17(14.9 \%)$ \\
\hline Purchases & $9(7.4 \%)$ & $21(18.4 \%)$ \\
\hline Animals & $21(17.2 \%)$ & $22(19.3 \%)$ \\
\hline- & $4(3.3 \%)$ & $5(4.4 \%)$ \\
\hline
\end{tabular}

\section{Conclusion}

In conclusion, our analysis has shown that the communicative interests of students from National Research Nuclear University MEPhI (Moscow Engineering Physics Institute) and Saint Petersburg State University of Civil Aviation в OSNs may be defined in the following way: 1) recreation, pastime; 2) communication, including acquaintance; 3) obtaining information (including new resource finding) from other members of the social network; 4) verifying ideas by means of participation in social network interactions via professional search; 5) social benefits gained from contacts (belonging, self-identification, social involvement, social acceptance etc.).

In accordance with Russian trends, OSNs are used by students of technical universities and colleges on a daily basis, total time spent there is 1 to 3 hours. As a rule, they have accounts in various OSNs, but, as is the case with most young people across Russia, VK, Instagram, Facebook rank highest with them. And though communication is considered by them to be the main social benefit of using OSNs, practically all the interviewed students have shown interest in accumulating own social and professional capital by means of OSNs. Thus, practically everyone confirmed that they are members of network communities targeted directly or indirectly at professional interests. It means that engineering students are very interested in professional network communities in OSNs, the majority of them is willing to use OSNs in their subsequent professional engagement. This is a signal to university teachers which are still using OSNs very timidly in the academic process. Within the walls of universities, OSN is still a means of online student-to-student communication, a source of university news, including changes in the schedule, sometimes it is a way of helping fellow students in their studies or everyday problems. 


\section{References}

[1] Biancani, S., \& McFarland, D. (2013). Networks Research in Higher Education, Educational Studies, 4, pp. 85-126.

[2] Newcomb, T. M. (1961). The Acquaintance process. Holt, Reinhart, and Winston. New York, p. 303.

[3] Friedkin, N., (1978). University Social Structure and Social Networks among Scientists, The American Journal of Sociology, 6(83), pp. 1444-1465.

[4] Kayes, I., \& Iamnitchi, A. (2017). Privacy and security in online social networks: A survey. Online Social Networks and Media, 3-4, pp. 1-21.

[5] Gubanov, D. A., Novikov, D. A., \& Chkhartishvili, A. G. (2010). Social networks: the models of informational influence, management and confrontation. Moscow, Russia: Publisher of physical and mathematical literature.

[6] Voloshinova, D. (2015). Analysis of articles devoted to the problems of social networks and the review of their applicability to pedagogy. Questions of Teaching Methods in High School, 18, pp. 116-126.

[7] Voronkin, S. (2014). Social networks: evolution, structure, analysis. Educational technologies and societies, 17(1), pp. 650-675.

[8] Patarakin, E. D. (2009). Social interactions and network training 2.0. NP "Modern technologies in education and culture." Moscow, Russia.

[9] Kallas, P. (02.08.2018). Top 15 most popular social networking sites and apps. Retrieved from https://www.dreamgrow.com/top-15-most-popular-social-networking-sites/.

[10] Kemp, S. (30.01.2018). Digital in 2018: world's internet users pass the 4 billion mark. Retrieved from https://wearesocial.com/blog/2018/01/global-digital-report-2018.

[11] Ibid.

[12] Levada-Centr. (2018). Social networks. Retrieved from https://www.levada.ru/2018/03/06/sotsialnyeseti/.

[13] BrAnalytics. (2018). Statistics of social networks. Retrieved from https://br-analytics.ru/statistics/author?hub_id $=3 \&$ date $=201803 \&$ country_id $=20 \&$ period_type $=$ month.

[14] Mediascope. (2017). A research into VK: a portrait of young people. Retrieved from https://corp.imgsmail.ru/media/files/vk-generation.pdf.

[15] TadViser. (2018). Social networks (Russia's market). Retrieved from http://www.tadviser.ru/index.php/Статья: Социальные_сети_(рынок_России)/. 